\title{
THE COST AND QUALITY OF LABORATORY AUTOMATION: A SYSTEMATIC REVIEW
}

\author{
Megadianty Mokoginta, Amal Chalik Sjaaf
}

Faculty of Public Health, Universitas Indonesia

\begin{abstract}
Background: An increased number of visit to health facilities increases the number of laboratory examination. Laboratories are required to achieve better efficiency, accuracy, standardization, quality, and patient safety. A strategy to meet this demand is laboratory automation. However, some laboratories are hesitant to implement laboratory automation because of high cost and quality. This study aimed to systematically review the cost and quality of laboratory automation.

Subjects and Method: A systematic review was conducted by searching articles from 2009 to 2019 using PubMed, Science Direct, and Scopus databases. The keywords were "laboratory automation", "clinical", "cost", and "quality". The inclusion criteria were: (1) Articles published in English language; (2) Research or review articles; (3) Published from January 2009 to July 2019. The articles were reviewed based on PRISMA flow diagram.

Results: Seven articles reported a decrease in cost due to laboratory automation. The decrease in cost was mainly due to a decrease in the number of employees needed for certain jobs. The quality aspect was mainly assessed using Turnaround Time (TAT). In routine test laboratory, quality through TAT showed an increase, whereas in citoexamination the results can still be validated according to the specified time. The first six months after the implementation of laboratory automation was a vulnerable time due to several factors, including untrained staff. Continuous improvement and close monitoring were needed at this time.

Conclusion: When implemented properly, laboratory automation can reduce cost and increase the quality.
\end{abstract}

Keywords: laboratory automation, clinical laboratory, cost, quality, turnaround time

Correspondence:

Megadianty Mokoginta. Faculty of Public Health, Universitas Indonesia, Depok, West Java, Indonesia. Email: megathayeb@gmail.com. Mobile: 0811435556.

The $6^{\text {th }}$ International Conference on Public Health

Best Western Premier Hotel, Solo, Indonesia, October 23-24, 2019 | 275

https://doi.org/10.26911/the6thicph.04.37 